\title{
Approaches to the robotization of agricultural mobile machines
}

\author{
Vladimir Serebrenny, Madin Shereuzhev and Ivan Metasov \\ Bauman Moscow State Technical University, Mechanical Engineering Department, Moscow, Russia
}

\begin{abstract}
Agriculture is the extremely important and developing economic movement in all times. Automation of agricultural machines occurs by different ways. One way is through the creation of specialized technical solutions for the required technological processes, another way is the construction of automatic agricultural machines, including mobile ones. The state of modern technology allows to create autonomous machines. The agriculture robotization trends are the high precision and unmanned farming. The article considers the issues of robotization of agricultural machinery. Stages of robotization of agricultural mobile machines were analyzed. The factors affecting the autonomous movement of mobile agrorobots were shown.
\end{abstract}

\section{Introduction}

Currently, the production efficiency increase and the replacement of people in the hard and dangerous works is gained through using automation and robotic systems [1].

Trends in agricultural production are attempts of introduction of precision agriculture technologies $[2,3]$ and unmanned production cycles of agricultural products.

In Russia there are researches of problems associated with the development of an agricultural robot for collect vegetable crops growing above the ground, such crops are cabbage, melons (watermelons), cucumbers, tomatoes, eggplants, peppers (e.g. [4]). There are attempts for creating robot for field state monitoring [5].

High productivity of agriculture machines in tasks (soil cultivation and sowing; fertilization; protection of plants from pests, diseases and weeds; harvesting of grain, legumes, oilseeds and groats; post-harvest processing of cereals, legumes, oilseeds and cereals, etc.) today is supported by:

- Increasing engine power,

- Increasing working width,

- Increased operating speed,

- Increased capacity,

- Automation of the process.

The only way to increase the efficiency of agricultural machinery without negatively affecting the soil is automation $[6,7]$.

Automation includes creation of control system for follow processes:

- Internal systems and processes control,

- Fleet control,

- Process chain control,

- Autonomous machines control.
Automation of agricultural machines occurs on the one hand through the creation of specialized technical solutions for the required technological processes, on the other hand, by construction of automatic agricultural machines [8,9], including mobile ones. Today's state of technics and technology allows to create not only automatic, but also autonomous machines. The trend is shifting from automation to the robotization of industries, which, within the agriculture, occurs by using high-precision farming $[10,11]$ and unmanned cycles of growing crops [12].

The efficiency of mobile agricultural machines is ensured by measuring, recording and controlling their parameters, protecting the main mechanisms, regulating and controlling the machine as a whole.

The automatic system of a mobile agricultural machine, as a rule, consists of the following main parts: an object (measurement, accounting, control, protection, regulation), a sensitive device, an amplifying converter, an actuator, a power source, an operator.

In the autonomous system, there is no human operator. The creation of autonomous mobile agricultural machines requires the addition of new elements in the design to carry the control signals from the control system to the actuators. In the robotic system, adaptability of the control system is assumed, which also causes the inclusion in the control system of the vision system, navigation system, etc.

\section{Robotization of traditional mobile agricultural machinery}

To analyze the stages of robotization of traditional agricultural equipment, we consider the basic stages of robotization of a tractor with an internal combustion engine (ICE). 


\subsection{Control levers}

Based on the previous experience [13, 14], for the robotization of the tractor with ICE, tractor control devices should primarily be provided with electronic control interfaces. This problem should be solved by using industrial servo drives. For the robotization of mobile agricultural machines, servos must be installed on the following controls:

- Throttle control lever,

- Steering control lever,

- Brake control levers,

- Transmission control levers,

- Clutch control lever,

- Control levers for hydraulic drives of attachments,

- Control levers for auxiliary systems (lighting, heating, etc.).

\subsection{Executive control system}

This system is necessary for interfacing high-level commands of the top-level control system, with commands applied to the servo drives of the controls levers. In addition, this system should provide monitoring of current parameters from on-board sensors, such as temperature, pressure, voltage, speed sensors. The main stages of the development of this system consist of:

- Selecting a microcontroller model,

- Development of a system for matching signals from airborne sensors, with a microcontroller,

- PCB development,

- Development of the management program.

\subsection{Upper level control system development}

It is advisable to build such a system as computer based because of the large computational load [15]. The main goals of this system are:

- Receiving and processing of information from sensors of the system of technical vision,

- Receiving and processing of information from sensors of the global positioning system,

- Receiving and processing information from other sensors, such as accelerometers and gyroscopes,

- Receiving and execution of commands from the operator's panel,

- Construction of the external environment model,

- Determination of the patency of the external environment,

- Solving the problems of mapping and localization,

- Trajectory planning,

- Submission of commands to the executive management system for trajectory development,

- Transfer of control commands to attachments.

\subsubsection{Selection of the software platform}

The architecture of the hardware platform, the number of required libraries for a specific operating system and the cost of work are the parameters that determine the choice of the operating system.

\subsubsection{Machine vision system sensors selection}

To obtain the necessary amount of data about environment, it is advisable to use a combination of a LIDAR and cameras as a vision system [16]. To obtain a wider range of information about the environment, ultrasound and ultraviolet sensors can be added to the system.

\subsection{Power system development}

When developing a mobile robot power system, the following points should be considered:

- Voltage range of the on-board network,

- The range of permissible supply voltages for the control systems of the upper and lower levels,

- Power consumed by the upper and lower control systems,

- Excess of power in the on-board power supply network.

\subsection{Development of communication interfaces}

These interfaces are required for sending to the onboard upper level control system the tasks that the operator determines. In addition, these interfaces can be used for direct control.

\subsection{Development of parts for mechanical connection of chassis with mounted systems}

The main problem of this stage is the mechanical connection of the servo drives to the control levers.

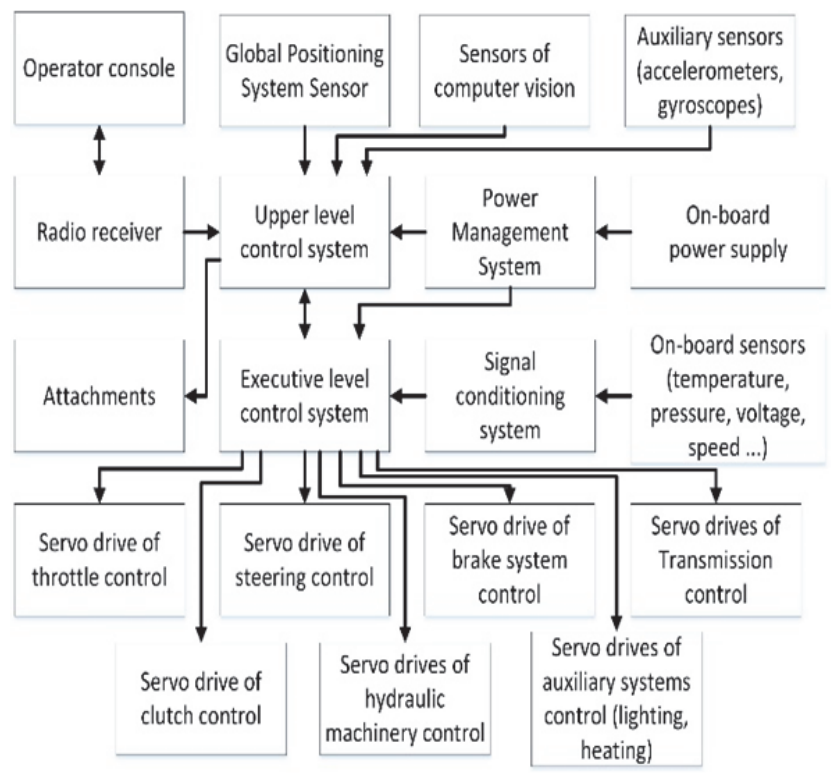

Fig. 1. Scheme of the robotized tractor with internal combustion engines. 
The resulting system has a large number of elements, which make it difficult to build such a system with high reliability. In addition, due to the installation of servos on the controls, it becomes difficult to control the tractor from the driver's cab. In Figure 1 the developed structural scheme of a robotic tractor with ICE is shown.

\section{Robotization of electric mobile agricultural machinery}

Thanks to the latest world trends in the electrification of vehicles, the first electric tractors have begun to appear recently [17] (Fig. ).

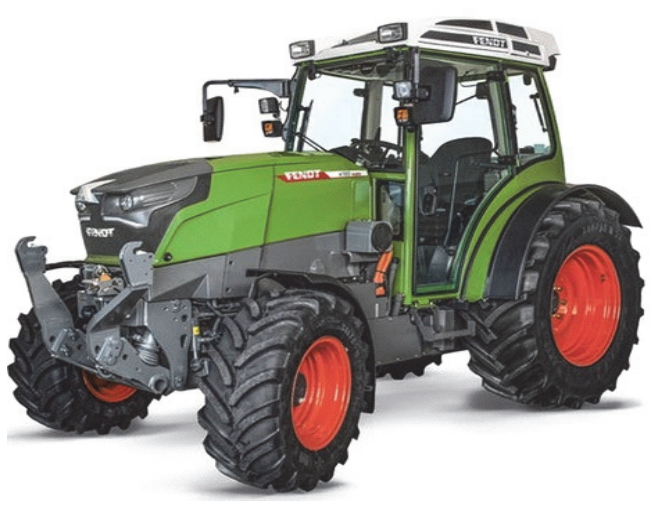

Fig. 2. Electric tractor Fendt e100 Vario.

For robotization of electric tractor control levers installation and executive control system for control levers are not required for electric tractor. On the electric tractor, a built-in control system with an electronic interface already exists. The main difference of this system for an electric tractor, from a system for a tractor with ICE, is a link with an existing on-board control system.

Stages of selection software platform, machine vision system sensors selection, power system and communication interfaces development are similar to those for the tractor with ICE.

Stage of development of parts for mechanical connection of chassis with mounted systems for electric tractor is much easier compared to a similar stage for a tractor with ICE, because there is no need for a mechanical connection of servos with control levers.

The amount of elements for the robotized electric tractor control system is much less, than the one of tractor with ICE. This simplifies autonomous control system creation for electric tractor, and provides higher reliability of this machinery.

In Figure 3 the developed structural scheme of a robotic tractor with an electric motor is shown.

For mobile agriculture robot with ICE it is necessary to solve the problem of automated refueling, this process can be fire-dangerous.

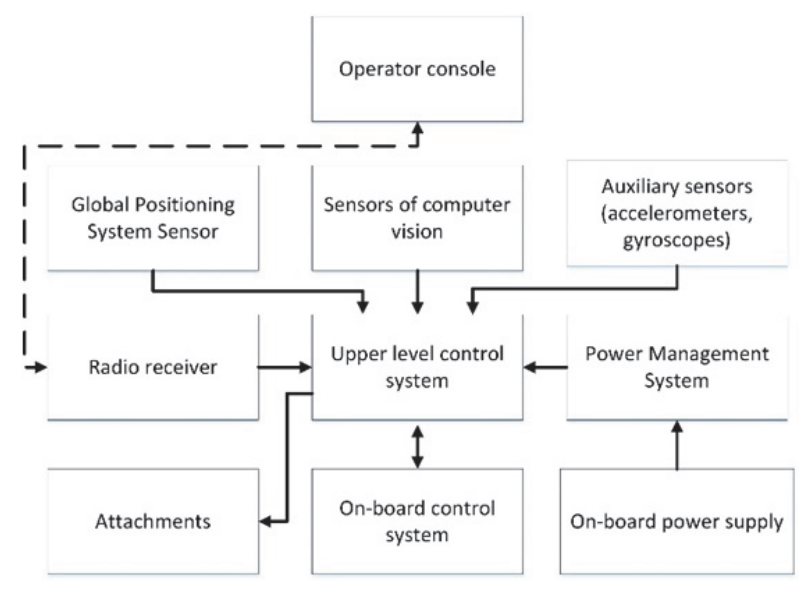

Fig. 3. Scheme of the robotized electric tractor.

In Figure 4 factors, affecting the straightness movements of the tractor is shown.

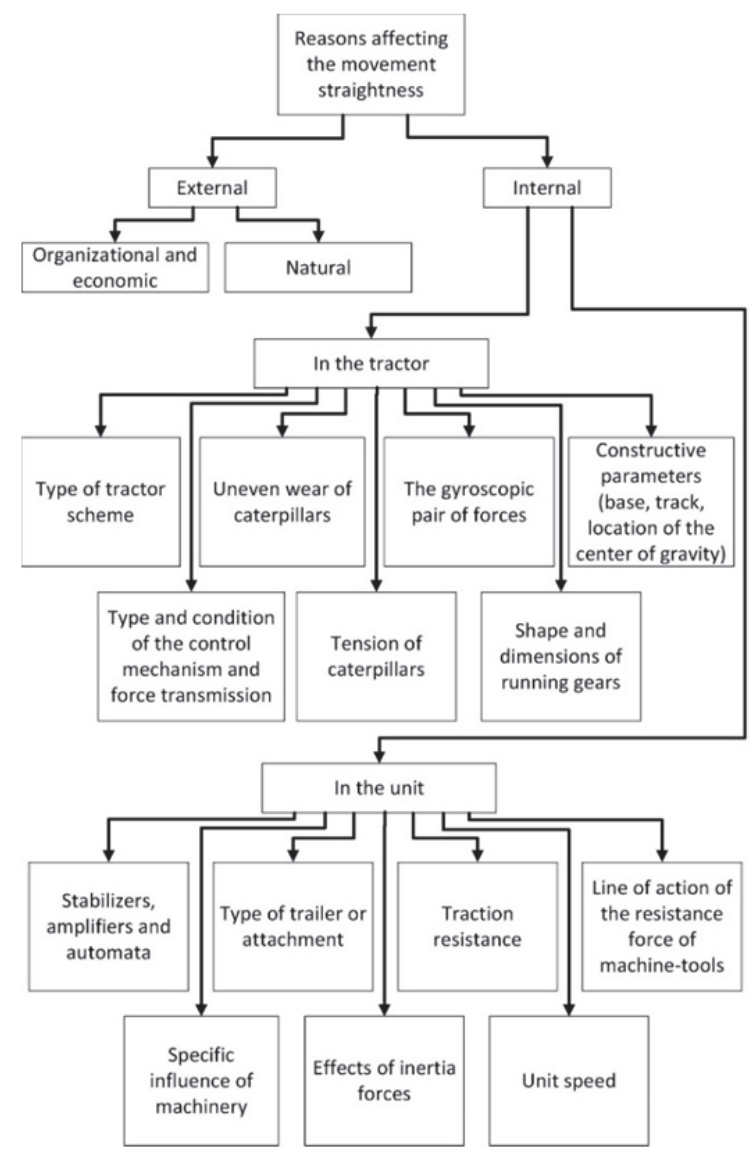

Fig. 4. Factors affecting the straightness movements of the tractor.

All reasons are divided into external and internal. Internal causes, such as "Type and condition of the control mechanism and force transmission", in the case of a tractor with ICE will have a stronger influence on the straightness of the movement. This is due to the complexities that will create control of the clutch and transmission, as well as the nonlinearity of the ICE. 


\section{Conclusion}

In the work the analysis of the basic stages of robotization of mobile agricultural machinery is carried out. The result of the analysis is a functional diagram of the mobile robot control system for agricultural purposes. Based on experience in the field of robotization of military equipment, recommendations on the structural composition of the management system were formulated.

The comparative analysis of the complexity of the robotization of mobile agricultural equipment with ICE and electric drive was conducted, which showed a higher reliability of the robotic system with factory electronic controls and a lower cost of its robotization, and also showed the need to promote the electrification of agricultural machines to accelerate the robotization process.

\section{References}

1. T. Bock Construction Automation and Robotics, (InTech, 2008)

2. S. Blackmore From precision farming to phytotechnology. In I: Mechatronics \& Robotics '04, Aachen, Germany, (2004)

3. Drenjanac, D., \& Tomic, S. D. K. Middleware challenges in robotic fleets for precision agriculture.

Journal of Mechanics Engineering and Automation, 3(11), (2013).

4. Robotic system for harvesting vegetable crops growing above the ground, Internet Journal "Naukovedenie",3(40) vol. 9, (2017)

5. Development work on the creation of robotics farmland, Scientific Journal of KubSAU, 119(05), (2016)

6. P. Gonzalez-de-Santos, A. Ribeiro, C. FernandezQuintanilla, F. Lopez-Granados, M. Brandstoetter, S. Tomic, S. Pedrazzi, A. Peruzzi, G. Pajares, G. Kaplanis, M. Perez-Ruiz, C. Valero, J. del Cerro, M. Vieri, G. Rabatel, B. Debilde Fleets of robots for environmentally-safe pest control in agriculture, (Precision Agric, 2017)

7. J. F. Reid, Q. Zhang, N. Noguchi, and M. Dickson, "Agricultural automatic guidance research in North America," Computers and Electronics in Agriculture, vol. 25, (2000)

8. M. Perez-Ruiz, D. C. Slaughter, F. A. Fathallah, C. J. Gliever, B. J. Miller Co-robotic intra-row weed control system, (Elsevier, 2014)

9. S. J.Moorehead,C.K.Wellington, B. J. Gilmore, and C.Vallespi, Automating orchards: a system of autonomous tractors for orchard maintenance, in Proceedings of the IEEE International Conference of Intelligent Robots and Systems, Workshop on Agricultural Robotics, (2012)

10. A. Peruzzi, C. Frasconi, L. Martelloni, M. Fontanelli, and M.Raffaelli, Application of precision flaming to maize and garlicin the RHEA project, in Proceedings of the 1st International Conference on Robotics and associated HighTechnologies and Equipment for Agriculture (RHEA '12), Italy, (2012)

11. R. Eaton, J. Katupitiya, K. W. Siew, and K. S. Dang, Precision guidance of agricultural tractors for autonomous farming, in Proceedings of the 2nd Annual IEEE Systems Conference Proceedings (SysCon '08), pp. 314-321, April (2008)

12. A. T. Nieuwenhuizen, J. W. Hofstee, and E. J. van Henten, "Performance evaluation of an automated detection and control system for volunteer potatoes in sugar beet fields," Biosystems Engineering, vol. 107, no. 1, pp. 46-53, (2010)

13. A.N.Kutuzov, V.S.Lapshov V.P. Noskov, I.V. Rubcov Experience in developing and creating an autonomous intelligent robotic complex based on the T-72 serial tank, (Defense technology: scientific-technical, 2000)

14. A. V. Kalinin, V. P. Noskov, I. V. Rubcov The system for automative driving the tank T-72B, (Bulletin of BMSTU: Mechanical engineering, 2012)

15. V.V. Serebrenny, I.E. Metasov, M.A. Shereuzhev Development of the agricultural machinery robotization methods (News of KBNC RAN, 2017)

16. L. Zalud, P. Kocmanova, Fusion of Thermal Imaging and CCD Camera-based Data for Stereovision Visual Telepresence, Safety, Security, and Rescue Robotics (SSRR), (2013)

17. Electronic resource https://www.fendt.com//int/fendt-e100-vario.html 